\title{
Effect of Vacuum Residue on Rheological Properties of Low Viscosity Bituminous Binders for Road Construction
}

\author{
Ms. Khusboo Arora*, Mrs. Siksha Swaroopa Kar** \& Dr. P.K.Jain *** \\ Project fellow, Scientist, Chief Scientist and Professor \\ CSIR-Central Road Research Institute, Mathura Road, New Delhi
}

\begin{abstract}
In this paper effects of different dosage of a typical vacuum residue (VR) on rheological properties of low viscosity bituminous binder are investigated. Detailed rheological studies were performed using Dynamic Shear Rheometer (DSR). Four approaches were used to investigate the temperature susceptibility of binders. Temperature susceptibility decreases with increase in VR percentage in VG10 showing high penetration index $(P I)$, low viscosity-temperature susceptibility (VTS) and high penetration-viscosity number (PVN). Isochronal and isothermal graphs are plotted for different blends. From this study, it has been concluded that with the incorporation of VR in VG10, resistance to rutting in bituminous roads increases. VR modified bitumen shall perform better in high tempertaure climate.
\end{abstract}

\section{Introduction}

India is currently at a critical juncture in the history of infrastructure developments since independence, whereby road construction and developmental activities are at the peak. Intensive and high value road construction programs/schemes, under the aegis of National Highways Authority of India, National Rural Roads Development Agency, Ministry of Road Transport and Highways, State Public Works Departments and Ministry of Urban Development are currently under various stages of implementation. Flexible pavements with bituminous wearing coat are the most preferred and commonly used type of pavement construction in India, because of their reduced initial construction cost and possibility of their up-gradation through stage construction.

Bitumen is a black coloured hydrocarbon binder that binds aggregates in bituminous surfacing of flexible pavements on roads and airfields. Bitumen is also used in other construction applications, such as waterproofing, flooring and joint sealing. It is well known, that bitumen is a complex, stress and temperature dependant visco-elastic material consisting variety of large size hydrocarbon molecules. It is considered as a colloidal system consisting of high molecular weight asphaltene miscelles dispersed in a lower molecular weight dispersion medium (maltenes). Naphtenic crude oils give a large yield of bitumen that may be of good quality, while paraffinic crude oils may give a bitumen of acceptable quality or a bitumen which may not be suitable for road construction. Therefore, improvements in processing methods or use of suitable additives may improve properties of inferior quality bitumen produced from different crude sources.

India consumes about five million tons of viscosity graded paving bitumens in a year. The quality of bitumen to be used in road construction is required to be in conformity to standard. IS:73:2013specify, four grades of bitumen such as VG 10, VG 20, VG 30 and VG 40. Indian refineries are producing only two grades such as VG10 and VG30, which are not adequate for climate and traffic conditions prevailing in India. . IRC:372012 recommended use of harder grade such as VG 40/modified bitumen for pavement subjected heavy loading.

The distress such as cracking and rutting can be predicted by analysis of the rheological characteristics of bituminous binders ${ }^{1-2}$. These bituminous binders are visco-elastic in nature as they behave like a elastic solid at a moderate temperature, where the deformation due to the application of load is recoverable. At high temperature, bituminous binders act like a viscous material, exhibiting non-recoverable deformations. A viscoelastic material, on the other hand, exhibits an immediate deformation (elastic portion) followed by timedependant deformation (viscous portion). Once the load is removed, the elastic deformation is recovered at a decreasing rate, but the viscous deformation is not recovered ${ }^{1}$. Bituminous mixture must be able to resist primary modes of distress, namely, excessive permanent deformation (rutting) and fatigue cracking. As the mechanical properties of bituminous mixture are strongly dependent upon the properties of the binder, it has to fulfill certain mechanical and rheological requirements to ensure the performance of binders on $\operatorname{road}^{3}$.

Rheology, by definition, involves the study of the flow properties of time and temperature dependent visco-elastic materials, such as bitumen, that are stressed (usually under shear stress or extensional stress) through the application of force $e^{4-6}$. Bituminous material display wide variations with temperature and loading time in all these mechanical properties. Therefore, a study of their behavior is necessary over wide range of temperature and frequencies. To predict the mechanical performance of a bituminous binder, it is necessary to understand its stress-strain behavior under different environmental and loading conditions ${ }^{7}$. Frequency sweep and temperature sweep tests by dynamic shear rheometer are significant. Fronties et $\mathrm{al}^{8}$ conducted frequency 
sweep tests on selected bituminous binders and also on the mixtures. They presented $\mathrm{G}^{\prime}, \mathrm{G}^{\prime \prime}$ and $\delta$ as functions of loading frequency. The temperature sensitivity of bituminous binders can also be examined by performing temperature sweep tests as reported by Clyne and coworkers ${ }^{9-10}$. The importance of phase measurement in prediction of performance is given importance in US - SHRP performance based specification. The permanent deformation of bituminous surface can be controlled by a minimum value of $\left[\mathrm{G}^{*}\right] / \sin \delta$ in the high service temperature range ${ }^{11}$. A maximum value of $\left[\mathrm{G}^{*}\right] \cdot \sin \delta$ in the medium temperature range is important to reduce the risk of fatigue cracking. Bari and witczak ${ }^{12}$ have developed a models for viscosity and complex shear modulus of bituminous binders for mechanistic and also empirical pavement design guidelines. These models take into account the loading frequency at a specific temperature.

A black diagram is simply a plot of complex modulus versus phase angle obtained from a dynamic shear modulus test ${ }^{13-14}$. Therefore, visco-elastic data may be plotted over wide range of temperatures and frequencies using the black diagram. Measurement errors, changes in composition, or variations in bitumen structure can cause deviations in black diagram. This plot is therefore very useful for presenting the effect of modification on bitumen.Study of the effects of VR on rheological properties of VG10 towards development of harder grade bitumen for construction of base courses was felt essential to bridge the gaps in available bitumen binders and needs of pavement. Present study aims at prediction of performance of VG-10 bitumen modified by different doses of VR.

Materials:

\section{Experimental Study}

VG10 grade bitumen produced at IOCL Vadodra was used for the study. The physical properties of bitumen are described in Table 1. A typical VR was used to modify VG-10 bitumen. The physical properties of VR used for modification of VG 10 are given in Table 2.

\section{Methods}

Preparation of blends:

VG 10 bitumen was heated to a temperature of $150^{\circ} \mathrm{C}$ in a glass beaker and requisite quantity of VR heated to a temperature of $170^{\circ} \mathrm{C}$ was added to the melted VG 10 bitumen. Contents were then blended in a high speed stirrer at specific rpm for $2 \mathrm{hrs}$ at a temperature of $155^{\circ} \mathrm{C}$ till a homogenous blend was obtained. Six blends are prepared by varying VR percentage from 10 to 80 by the weight of blend. The physical properties of various blends determined according to IS 73 standard are given in Table 3. The compositions of selected blends are given in Table 4.

\section{Test Methods:}

The viscosity profile of the blended binders was measured using the Brookfield Rotational Viscometer, to study influence of the different dosage of residue on the viscosity of the VG 10 bitumen. The viscosity of VG 10 bitumen and blends was measured at $120^{\circ} \mathrm{C}, 135^{\circ} \mathrm{C}, 150^{\circ} \mathrm{C}, 170^{\circ} \mathrm{C}$, and $180^{\circ} \mathrm{C}$ temperatures at rotational speed of 20 RPM.

The visco-elastic response of the blends were evaluated using Dynamic Shear Rheometer (DSR) with parallel plate geometry by measuring complex shear modulus $\left(\mathrm{G}^{*}\right)$ and Phase angle $(\delta)$. A $25 \mathrm{~mm}$ a steel plate was used with a gap width of $1 \mathrm{~mm}$ and the measurements were taken at a frequency of $10 \mathrm{rad} / \mathrm{sec}$ with a strain level of $10 \%$. . Frequency sweep was conducted in the frequency range of $0.1-25 \mathrm{~Hz}$ at different temperatures $\left(50-80^{\circ} \mathrm{C}\right)$ with $10^{\circ} \mathrm{C}$ increment and temperature sweep test was done at temperature range of $50-80^{\circ} \mathrm{C}$ conducted at 0.1 and $0.4 \mathrm{~Hz}$ with a strain level of $1 \%$. Frequency sweep and temperature sweep plots are also known as isochronal and isothermal plots respectively.

An isochronal plot is defined as an equation or a curve on a graph representing the behavior of the system at a constant frequency (time of loading) and an isothermal plot is described as an equation or a curve on a graph representing the behavior of a system at a constant temperature ${ }^{15}$. For a dynamic experiment, a graph of the magnitude (or norm) of the complex shear modulus $\left(\left|\mathrm{G}^{*}\right|\right)$ versus the phase angle $(\delta)$ is called a Black diagram ${ }^{16-17}$. The samples are prepared by pouring the bitumen into silicon molds with the appropriate geometry for the type of material to be tested.

\section{Temperature Susceptibility:}

Bituminous binders display thermoplastic properties, i.e. they become soft when heated and hard when cooled. Several equations exist those define the way that the viscosity (or consistency) changes with temperature ${ }^{18-19}$. In the present study, four approaches are used to determine temperature susceptibility of the VG10 and blends of VR-VG 10.

(a) Penetration Index (PI) 
Pfeiffer and Van Doormaal developed an equation for the determination of temperature susceptibility that assumes a value of about -2 to +2 for road bitumens ${ }^{20}$. For this reason, they defined the penetration index (PI) by following equqtion

$$
\mathrm{PI}=\frac{20(1-25 \mathrm{~A})}{1+50 \mathrm{~A}}
$$

Where A is temperature susceptibility and the PI is an unequivocal function of A. The values of A and PI can be derived from penetration measurements at a temperature $T_{1}$ and softening point, using the equation:

$$
A=\frac{\log \text { pen at } \mathrm{T}_{1}-\log 800}{T_{1}-\text { ASTM softening point }}
$$

\section{(b). Penetration-Viscosity Number (PVN)}

The penetration-Viscosity ${ }^{21}$ number is another method used to determine the temperature susceptibility of bitumens. This number is based on penetration value at $25{ }^{\circ} \mathrm{C}$ and viscosity at $135^{\circ} \mathrm{C}$, using following equation

$$
P V N=\frac{L-X}{L-M}(-1.5)
$$

Where: $\mathrm{X}=$ the logarithm of viscosity in centistokes measured at $135^{\circ} \mathrm{C}$

$\mathrm{L}=$ the logarithm of viscosity at $135^{\circ} \mathrm{C}$ for a PVN of 0.0

$\mathrm{M}=$ the logarithm of viscosity at $135^{\circ} \mathrm{C}$ for a PVN of -1.5

\section{(c). Viscosity - Temperature Susceptibility}

The Viscosity-Temperature Susceptibility (VTS) value for measuring temperature susceptibility of a bitumen sample was determined using the following equation:

$$
\text { VTS }=((\log (\log \text { Vis at T2) }))-(\log (\log \text { Vis at T1 }))) /(\log T 1-\log T 2))
$$

\section{(d). Using $G^{*}$ Approach}

The ideal system should not only exhibit enhanced resistance to deformation, pronounced elastic recoil but also have a small temperature gradient of the modulus. In the case of a straight bitumen one can interchange $\eta$ and $G^{*}$ due to insignificant elasticity at elevated temperatures. Temperature susceptibility can be calculated using the following equation according to Bouldin and Collins ${ }^{22}$.

$$
\beta^{*}=\log \left(G^{*}{ }_{1}-G^{*}{ }_{2}\right) /\left(T_{1}-T_{2}\right)
$$

\section{Effect of VR on physical properties of VG10}

\section{Results and Discussions}

Effect of VR on viscosity and penetration of VG-10 is shown in Figure 1. It can be seen from the plot that with increase in VR, viscosity of blend increases and penetration decreases. Effect of VR on softening point is shown in Figure 2. The softening point of VG 10 increases with increasing in concentration of VR in VG 10. From the plots, it can be concluded that with increasing percentage of VR, VG 10 transform to a harder grade bitumen.

\section{Effect of VR on viscosity and temperature susceptibility}

Viscosity is a fundamental characteristic that describes the resistance of fluids to flow. In practice, it is necessary to ensure that bituminous binder has desired viscosity to ease pumping and be able to coat aggregate during mixing. The relationships between viscosities of different blends at different temperature are shown in Figure 3. The VTS, PVN, $\beta^{*}$ and PI values of the blends and VG 10 are given in Table 5. Data given in Table 5 indicate that temperature susceptibility of bitumen decreases with increasing VR content in VG 10 grade bitumen, eventually better performance of roads.

\section{Rheological properties}

Results given in Figures 4 (a) and 4 (b) show a decrease of $G^{\prime}$ and $G^{\prime \prime}$ moduli with increasing temperatures. The increase in $\mathrm{G}^{\prime}$ reflects the increase in the stiffness of the blends, compared with that of VG 10. But the increase in $\mathrm{G}^{\prime \prime}$ indicates an increase in the viscous response.

Figure 4 (c) shows almost linear relationship between complex modulus $\left[\mathrm{G}^{*}\right]$ and temperature. The VG 10 showed lower value for complex modulus compared to the blends. Figure 4 (d) shows a similar trend of complex viscosity and complex modulus. The complex viscosity reduces with increasing temperatures.

Figure 4(f) shows that the phase angle ( $\delta$ ) of blends was lower than that of VG 10. Lower phase angle indicates lower viscous flow and higher elastic response. This indicates that blends have comparatively high consistency and elasticity. Figure 4(e) shows that there is an increase in the $\mathrm{G}^{*} / \sin \delta$ parameter of the VG 10 when it is blended with VR. This indicates that the stiffness of the blends increases with the increase in the percentage of VR and also decreases with the increase of the temperature of test. 
Storage modulus $\left(\mathrm{G}^{\prime}\right)$ and the complex modulus $\left(\mathrm{G}^{*}\right)$ at $60^{\circ} \mathrm{C}$ are shown in Table 6 . As elasticity of binder mentioned earlier, $G^{*}$ is measure for overall resistance of the binder to flow, while $G^{\prime}$ is an indicator how much binder can recover after having been loaded. Hence good rutting resistance is expected if both $\mathrm{G}^{*}$ and G'are large. From Table 6, it can be seen that with increase in VR percent rutting resistance increases. Blend A and Blend $B$ are showing similar $G^{*}$ value, but Blend $B$ has lower $G^{\prime}$ value. If two systems have similar values of $G^{*}$ the system with larger $G^{\prime}$ should exhibit less rutting due to more pronounced recoil. Hence Blend $B$ will exhibit less rutting due to elastic recoil.

\section{Dissipation Energy}

During each cycle of traffic loading, a certain amount of work is being done in deforming the surface layer. Part of this work is recovered in elastic rebound of the surface layer, while the remaining work is dissipated in the term of permanent deformation and heat. To minimize rutting, the work dissipated during each loading cycle should be minimized. For a visco-elastic material, the work dissipated per cycle $\left(\mathrm{W}_{\mathrm{c}}\right)$ can be calculated as follows:

$$
\mathrm{W}_{\mathrm{C}}=\pi \cdot \sigma \cdot \varepsilon \cdot \operatorname{Sin} \delta
$$

For a strain-controlled cyclic loading, $\mathrm{W}_{\mathrm{c}}$ is directly related to $\mathrm{G} * / \operatorname{Sin} \delta$ :

$$
\mathrm{W}_{\mathrm{C}}=\pi \cdot \sigma_{\mathrm{o}}^{2} \cdot\left[\frac{1}{G * / \sin \delta}\right]
$$

The dissipation energy for different blends are shown in Figure 5. At lower temperature, dissipation energy is high but with increasing temperature, dissipation energy decreases.

\section{Temperature sweep test}

Figure 6 shows the isochronal plots for complex modulus, $\mathrm{G}^{*}$ for the VG 10 and blends ((a) for $0.1 \mathrm{~Hz}$ and (b) for $0.4 \mathrm{~Hz}$ ). In general, the absolute value $\mathrm{G}^{*}$ decrease with the increase of temperature. Figure 9 isochronal plots of complex modulus shows that the as the frequency increases, the complex modulus increases for all the blends and also with increase in VR, complex modulus increases. At $50^{\circ} \mathrm{C}, 0.1 \mathrm{~Hz}$ complex modulus for VG 10 is $0.528 \mathrm{kPa}$. Blend A shows $100 \%$ increase in complex modulus value as of VG 10 at lower temperature. Complex modulus for Blend B, C and D are $1.12,1.29$ and $1.49 \mathrm{kPa}$ respectively at $50^{\circ} \mathrm{C}$. Similarly for higher frequency for $0.4 \mathrm{~Hz}, \mathrm{G}^{*}$ values of Blend $\mathrm{C}$ and $\mathrm{D}$ were less compared Blend B.

\section{Frequency Sweep Test}

Isothermal plots are the graph between the frequencies versus complex modulus at constant temperatures. From these graphs it shows that, as the frequency increases, the $\mathrm{G}^{*}$ is increasing and also it shows that the after frequency of $15 \mathrm{~Hz}$, temperatures of all the blends shows the linear behavior. From the graphs it was also found, that $\mathrm{G}^{*}$ was decreasing with increase in temperature. At frequency $1.5 \mathrm{~Hz}$, which simulates to $80 \mathrm{~km} / \mathrm{hr}$ vehicle, VG 10 showed $0.085 \mathrm{kPa}$ complex modulus. Whereas, complex modulus for Blend A increased by $100 \%$ showing a value of $0.17 \mathrm{kPa}$. Similarly complex modulus for Blend B, Blend C and Blend D are $0.18,0.21$ and $0.28 \mathrm{kPa}$ respectively. Further addition of VR shows no much increase in complex modulus compared to $12 \%$ addition of VR. Phase angle values were increased from $72^{0}$ to $79^{0}$ with increase of frequency 0 to $25 \mathrm{~Hz}$. For different temperature, phase angle values were in between 72 to 79 showing no much change in viscous property. With increase in $10^{\circ} \mathrm{C}$ temperature, complex modulus decreased by three times that of previous temperature value.

\section{Black diagram}

The values of $\left|\mathrm{G}^{*}\right|$ and $\delta$, measured with the different sample geometries, have also been plotted in the form of a Black diagram in Fig. 8. VG 10 binder shows higher modulus for phase angle compared to prepared blends. At $50^{\circ} \mathrm{C}$ temperature, VG 10 was showing higher complex modulus at low phase angle compared to VG10 and VR blends. But with increase in temperature, blends behave oppositely showing higher modulus compared to VG 10, indicating better rutting resistance of blends.

The following conclusions are drawn from the study.

\section{Conclusion}

i. Incorporation of vacuum residue in VG 10 leads to value addition for better performance.

ii. Temperature susceptibility of blends of VR and VG 10 is lower as compared to VG 10 which, predicts better performance, indicating development of multi grade character in blends.

iii. Rheological investigations indicate that blends posses improved elastic response as compared to conventional VG 10 bitumen, which would be useful in reducing rutting at high pavement temperature.

iv. Black diagram shows the deviation of purely elastic modulus by extrapolating the curve to zero phase angle. Black diagrams of blends also indicate improved performance at higher pavement temperature, due to improvement in elastic character of blends. 


\section{Acknowledgements}

Authors are thankful to Dr. S.Gangopdhayay for kind permission to publish this paper.

\section{References}

[1]. Roberts, F. L., P. S. Kandhal, D. Lee, and T. W. Kennedy. 1996. "Hot Mix Asphalt Materials, Mixture, Design, and Construction," $2^{\text {nd }}$ Edition, Napa Education Foundation, Lanham, Maryland (USA).

[2]. Soleymani, H. R., H. Zhai, and H. Bahia. 2004. "Role of Modified Binders in Rheology and Damage Resistance Behavior of Asphalt Mixtures," Transportation Research Record: Journal of Transportation Research Board, No. 1875, TRB, National Research Council, Washington, D.C. (USA). 70-79.

[3]. Airey, G.D. Chapter 23: Bitumen Properties and Test Methods. ICE Manual of Construction Materials, Institution of Civil Engineers, UK, 2009.

[4]. Barnes, H.A., Hutton, J.F. and Walters, K. An Introduction to Rheology, Volume 3.Netherland; Elsevier Science Publishers, B.V., 1989.

[5]. Airey, G.D. Rheological Characteristics of Polymer Modified and Aged Bitumens. PhD Thesis, the University of Nottingham, 1997.

[6]. Saleh, F.M. Effect of Rheology on the Bitumen Foam-ability and Mechanical Properties of Foam Bitumen Stabilised Mixes. International Journal of Pavement Engineering, Vol. 8 (2), pp. 99-110, 2007.

[7]. Airey, G. D., B. Rahimzadeh, and A. C. Collop. 2002. "Linear Viscoelastic Limits of Bituminous Binders," Journal of the Association of Asphalt Paving Technologists, 71, 89-115.

[8]. Fronties, L. P. T. L., P. A. Pereira, J.C. Pais, and G. Trichês. 2006. "Behavior of Asphalt Rubber Mixtures with Different Crumb Rubber and Asphalt Binder Sources,” Asphalt Rubber Conference, San Diego, CA (USA).

[9]. Clyne, T. R., and M. O. Marasteanu. 2004. "Inventory of Properties of Minnesota Certified Asphalt Binders," Technical Report MN/RC-2004-35, Minnesota Department of Transportation, St. Paul, MN (USA).

[10]. Zhai, H., D. Salomon, and E. Miliron. 2006. "Using Rheological Properties to Evaluate Storage Stability and Setting Behavior of Emulsified Asphalts,” Idaho Asphalt Supply, Inc. White Paper, Idaho (USA).

[11]. Shin-Che Huang, Thomas F. Turner,Francis P. Miknis, and kennath p. Thomas Long Term Aging Characteristics of Polyposphoric Acid-Modified asphalts, Transportation research Record:Journal of The Transportation Research Board, No. 2051, D.C., 2008,pp. $1-7$

[12]. Bari J and Witczak M. W., New predictive models for viscosity and complex shear modulus of Ashphalt binder, Transportation Research Record: Journal of the transportation research Board, No 2001, 9-19 (2008)

[13]. Glossary of Rheological Terms - A Practical Summary of the Most Common Concepts, Rheology of Bituminous Binders, Edited by Eurobitumen, 1996

[14]. Hayton, B., "Bitumen Rheology and the Bohlin Dynamic Shear Rheometer" Scott Wilson Pavement Engineering, pp. 1-13, 1998.

[15]. Zanzotto, L., Stastna, J., and Ho, K., "Characterization of Regular and Modified Bitumens via their Complex Moduli" Journal of Applied PolymerScience, vol. 59, pp. 1897-1905, 1996.

[16]. Eurobitume. Rheology of Bituminous Binders Glossary of Rheological Terms: A Practical Summary of the Most Common Concepts, European Bitumen Association, 1996.

[17]. Airey, G.D. Use of Black Diagrams to Identify Inconsistencies in Rheological Data. Road Materials and Pavement Design, Vol. 3 (4), pp. 403-424, 2002a.

[18]. Airey, G.D. Rheological Evaluation of Ethylene Vinyl Acetate Polymer Modified Bitumens. Construction and Building Materials, Vol. 16, pp. 473-487, 2002b.

[19]. Roberts, F.L., Kandhal,P.S., Brown, E.R., Lee, D.Y. 1991 Hot Mix Asphalt Materials, Mixture Design and Construction,Napa Educational Foundation, Lanham, Maryland, USA

[20]. Van Der Poel, C., "A General System Describing the Visco-Elastic Properties of Bitumens and its Relation to Routine Test Data" Journal of AppliedChimistry, vol. 4, pp. 221-236, 1954.

[21]. Mcleod, N. W., "A 4 Year Survey of Low Temperature Transverse Pavement Cracking on Three Ontario Test Roads" Proceedings of the Association of Asphalt Paving Technologists, vol. 41, pp. 424-493, 1972.

[22]. Bouldin M. G. and Collins J. H, Influence Of Binder Rheology on Rut Resistance Of Polymer Modified And Unmodified Hot Mix Asphalt.

\section{LIST OF FIGURES:}




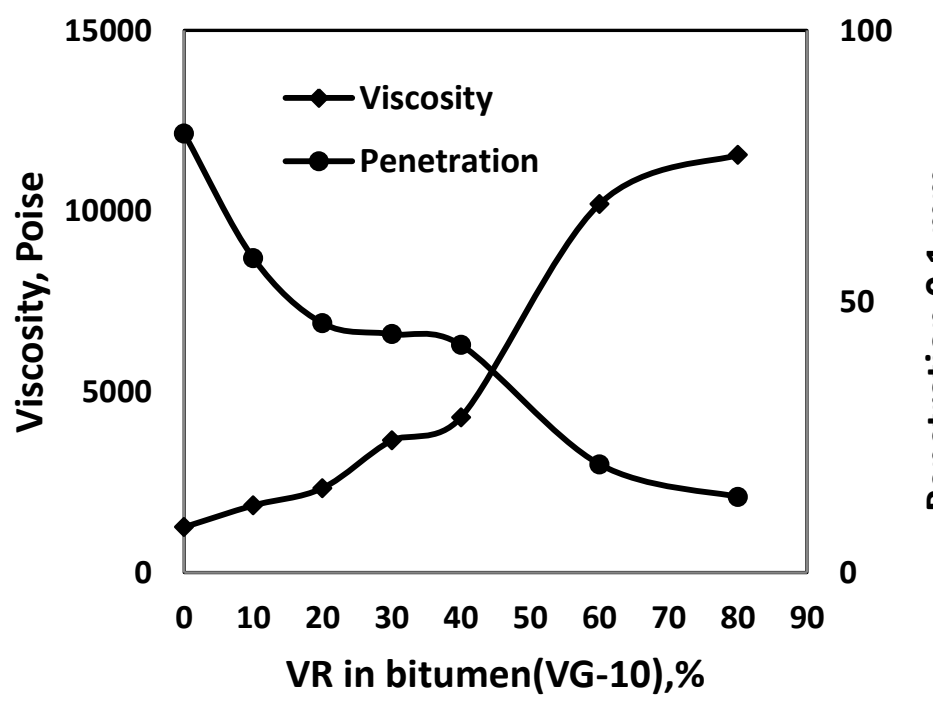

Figure 1: Effect of VR on viscosity and penetration

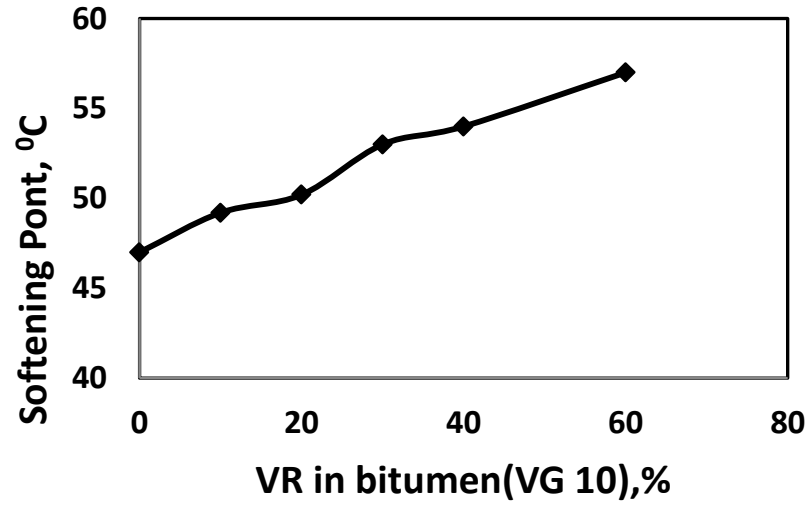

Figure 2: Effect of VR on softening point of VG - 10

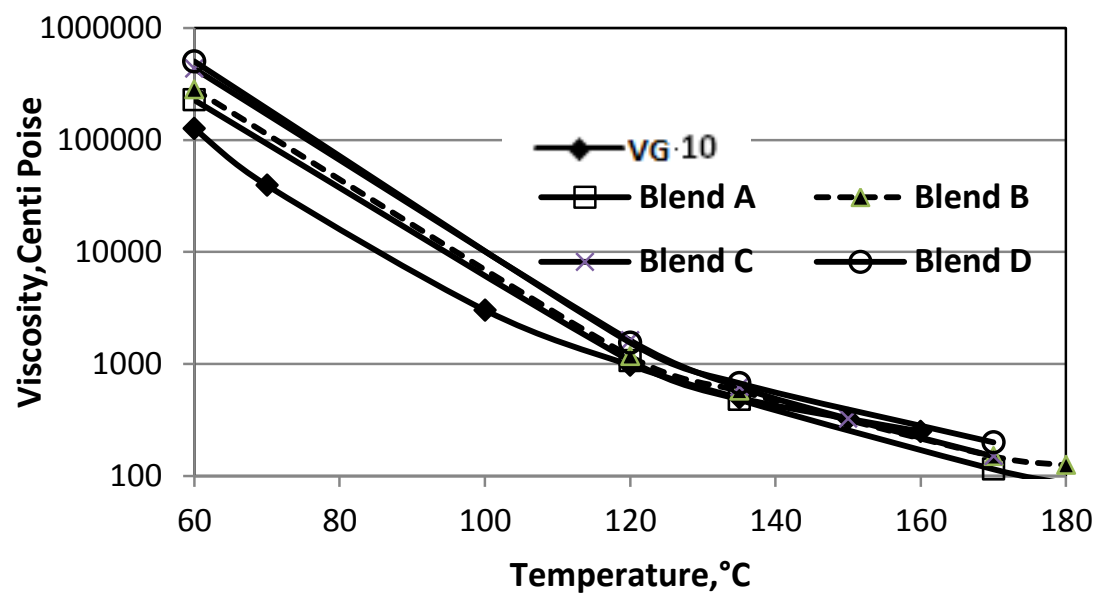

Figure 3: Temperature viscosity curves of different blends 

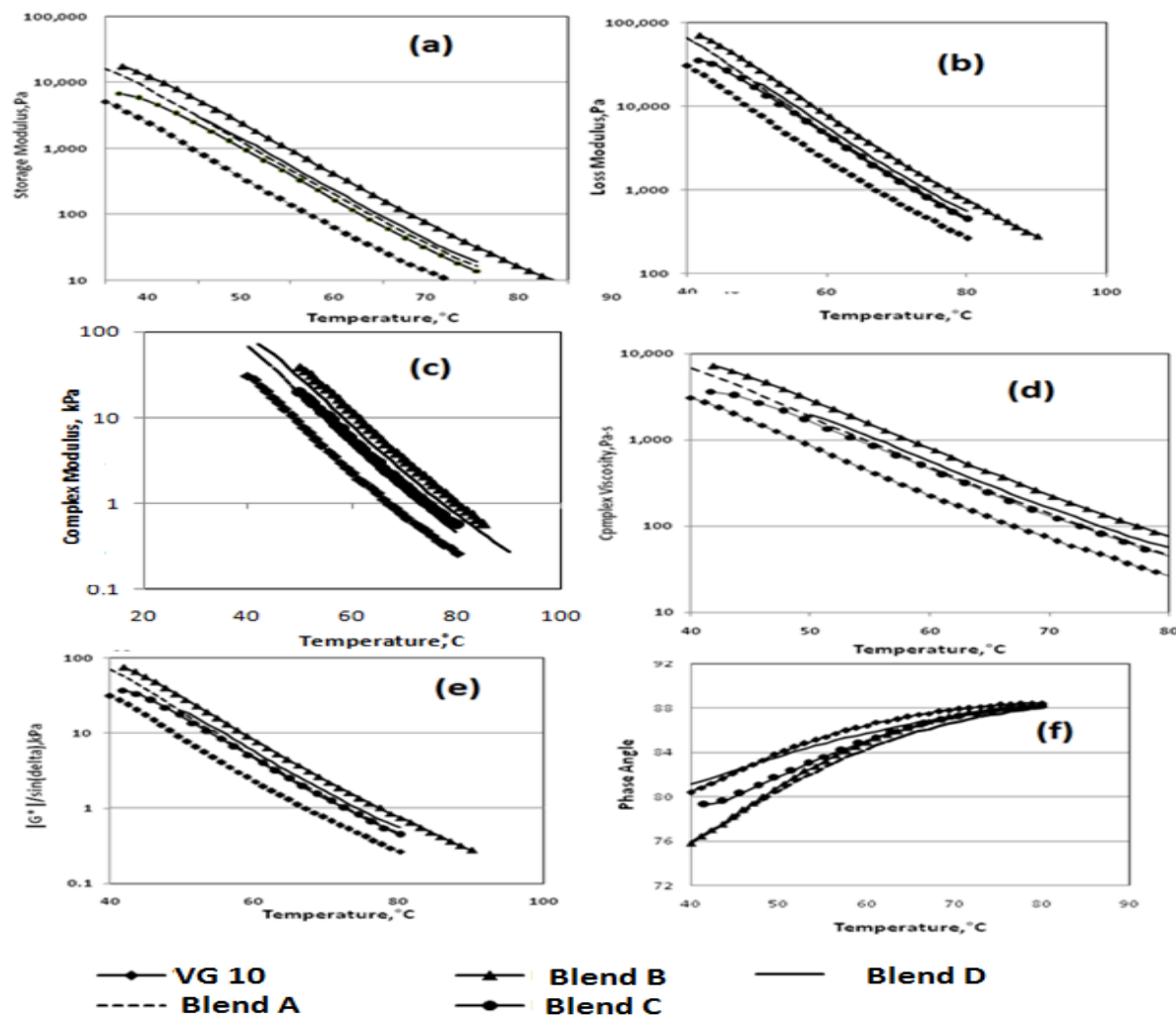

Blend D

Figure 4: Rheological properties of different blends with respect to temperature (a) Storage Modulus (b) Loss Modulus (c) Complex Modulus (d) Complex Viscosity (e) G*/sin $\delta$ (f) Phase Angle

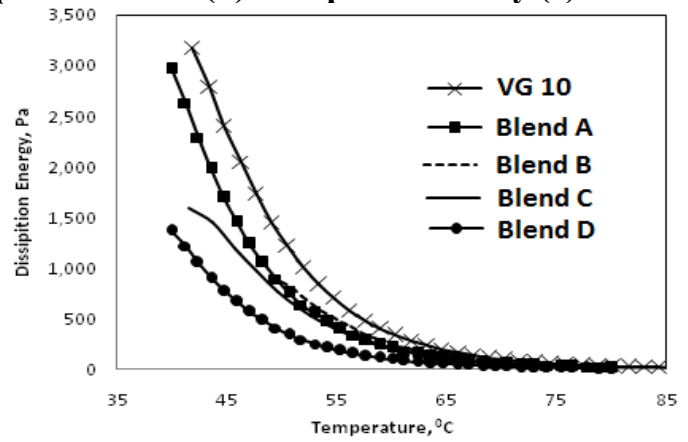

Figure 5: Dissipation energy variation with respect to temperature
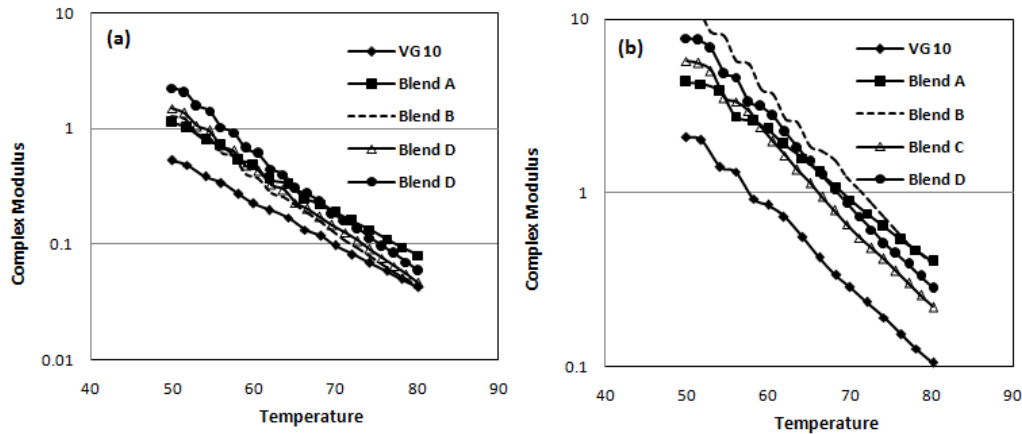

Figure 6: Isochronal plots for complex modulus, $\mathrm{G}^{*}$ (a) at $0.1 \mathrm{~Hz}$ (b) at $0.4 \mathrm{~Hz}$ 

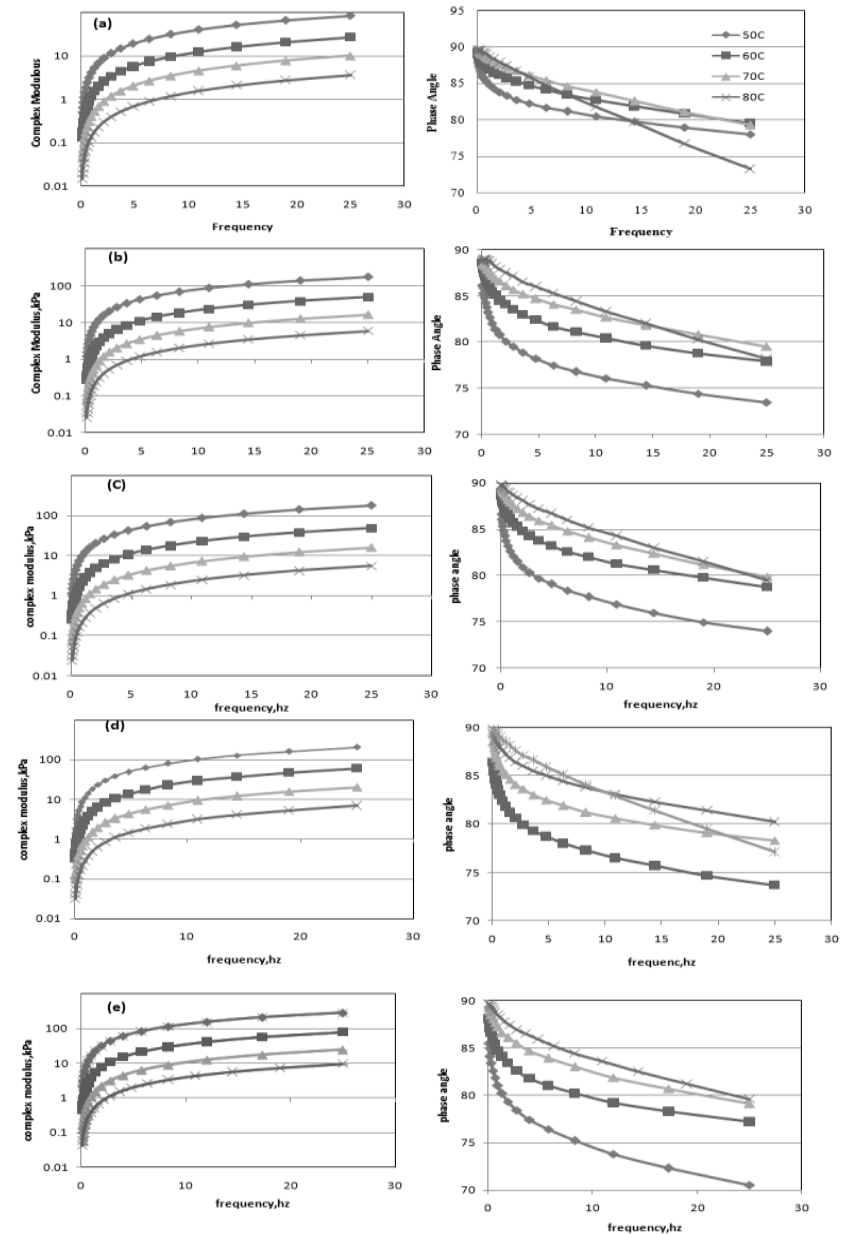

Figure 7: Isothermal plots complex modulus and phase angle, (a) VG 10 (b) Blend A (c) Blend B (d) Blend C (e) Blend D

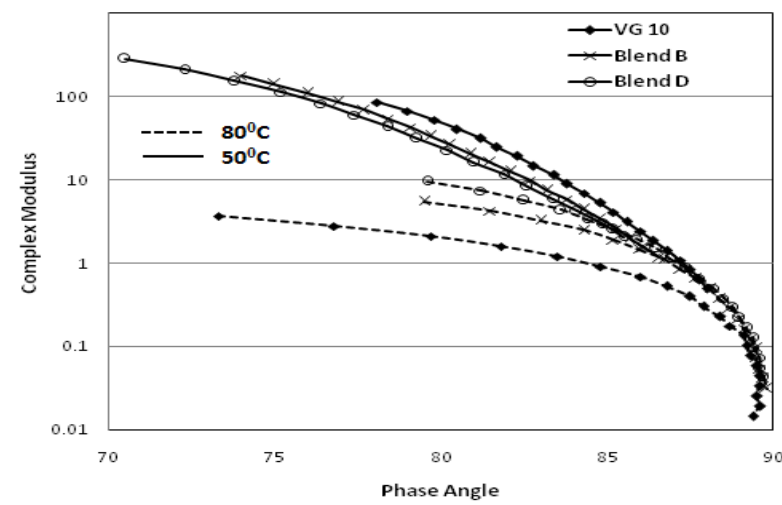

Figure 8: Black Diagram for VG 10 and prepared blends at $80^{\circ} \mathrm{C}$ and $50^{\circ} \mathrm{C}$

\section{LIST OF TABLES:}

Table 1: Properties of bitumen (VG 10) used in the present study

\begin{tabular}{llll}
\hline Properties & Test Method & Value & $\begin{array}{l}\text { Specification(IS:73) } \\
73: 2006\end{array}$ \\
\hline Penetration, $\left(25^{\circ} \mathrm{C}, 100 \mathrm{~g}, 5 \mathrm{~s}\right), 0.1 \mathrm{~mm}$ & IS 1203 & 81 & $80(\mathrm{Min})$. \\
Softening point (Ring and Ball), ${ }^{\circ} \mathrm{C}$ & IS 1205 & 44 & $40(\mathrm{Min})$. \\
Ductility at $25^{\circ} \mathrm{C}, \mathrm{cm}$ & IS 1208 & $100+$ & $75(\mathrm{Min})$. \\
Specific gravity , g/cc & IS 1202 & 1.001 & 0.99 (Min) \\
Viscosity at $60^{\circ} \mathrm{C}$, Poise & IS 1206 & 1150 & $800-1200$ \\
Viscosity at $135^{\circ} \mathrm{C}, \mathrm{cSt}$ & IS 1206 & 400 & $250(\mathrm{Min})$. \\
\hline
\end{tabular}


Table 2: Properties of VR

\begin{tabular}{lcc}
\hline \multicolumn{1}{c}{ Properties } & Test Method & Value \\
\hline Penetration, $\left(25^{\circ} \mathrm{C}, 100 \mathrm{~g}, 5 \mathrm{~s}\right), 0.1 \mathrm{~mm}$ & IS 1203 & 10 \\
Softening point $($ Ring and Ball $),{ }^{\circ} \mathrm{C}$ & IS 1205 & 61 \\
$\mathrm{G}^{*} / \mathrm{sin} \delta$ at $82^{\circ} \mathrm{C}, \mathrm{kPa}$ & ASTM D 7175 & 2.19 \\
& & 1350 \\
Viscosity at $135^{\circ} \mathrm{C}$, Centi Stokes & IS 1206 & 1950 \\
\hline
\end{tabular}

Table 3: Properties of the blends obtained by blended VG-10 with VR in different ratio

\begin{tabular}{|c|c|c|c|c|c|c|c|}
\hline \multirow[b]{2}{*}{ Properties } & \multirow[b]{2}{*}{ Test Method } & \multicolumn{6}{|c|}{ Blend Numbers. } \\
\hline & & 1 & 2 & 3 & 4 & 5 & 6 \\
\hline VR $(\%)$ & - & 10 & 20 & 30 & 40 & 60 & 80 \\
\hline VG $10(\%)$ & - & 90 & 80 & 70 & 60 & 40 & 20 \\
\hline $\begin{array}{c}\text { Penetration, } 25^{\circ} \mathrm{C}, 100 \mathrm{~g}, 5 \mathrm{~s}, \\
0.1 \mathrm{~mm}\end{array}$ & IS 1203 & 58 & 46 & 44 & 42 & 20 & 14 \\
\hline $\begin{array}{c}\text { Softening point (Ring and } \\
\text { Ball), }{ }^{\circ} \mathrm{C}\end{array}$ & IS 1205 & 47 & 49 & 50 & 53 & 57 & 62 \\
\hline Viscosity at $60^{\circ} \mathrm{C}$, Poise & IS 1206 & 1860 & 3660 & 4300 & 4300 & 9350 & 10520 \\
\hline Viscosity at $135^{\circ} \mathrm{C}, \mathrm{cSt}, \mathrm{min}$ & IS 1206 & 435 & 580 & 620 & 620 & 835 & 1025 \\
\hline $\begin{array}{c}\text { Viscosity ratio after RTFOT } \\
\text { at } 60^{\circ} \mathrm{C}\end{array}$ & IS 1206 & 1.43 & 1.54 & 1.58 & 1.89 & 1.56 & 1.75 \\
\hline
\end{tabular}

Table 4: Classification and nomenclature of selected blends

\begin{tabular}{ccl}
\hline$\%$ of VR & \% of VG 10 & Name of blend \\
\hline 12 & 88 & Blend A \\
25 & 75 & Blend B \\
35 & 65 & Blend C \\
48 & 52 & Blend D \\
\hline
\end{tabular}

Table 5: Softening Point, penetration and Temperature susceptibility parameters of VG 10 and blends

\begin{tabular}{lcccccc}
\hline & $\begin{array}{c}\text { Softening } \\
\text { Point }\end{array}$ & Penetration & VTS & PVN & PI & $\boldsymbol{\beta}^{*}$ \\
\hline VG-10 & 44 & 81 & 2.92 & 0.14 & -1.71 & 0.013 \\
Blend A & 48 & 56 & 2.32 & 0.96 & -1.45 & 0.019 \\
Blend B & 51 & 42 & 2.23 & 1.07 & -1.33 & 0.019 \\
Blend C & 53 & 34 & 1.51 & 1.35 & -1.30 & 0.021 \\
Blend D & 55 & 28 & 1.45 & 1.65 & -1.24 & 0.020 \\
\hline
\end{tabular}

Table 6: $\mathrm{G}^{*}$ and $\mathrm{G}^{\prime}$ value at $60^{\circ} \mathrm{C}$.

\begin{tabular}{lll}
\hline & $\mathrm{G}^{*}(\mathrm{kPa})$ & $\mathrm{G}^{\prime}(\mathrm{kPa})$ \\
\hline VG-10 & & \\
Blend A & 2.24 & 0.139 \\
Blend B & 4.72 & 0.469 \\
Blend C & 4.96 & 0.326 \\
Blend D & 5.14 & 0.483 \\
\hline
\end{tabular}

